\title{
Comparative Study of Mast Cell Count in Oral Reactive Lesions and Its Association with Inflammation
}

\author{
Hamideh KADEH, Ghazal DERAKHSHANFAR, Shirin SARAVANI \\ Department of Oral \& Maxillofacial Pathology, Oral and Dental Disease Research Center, School of Dentistry, Zahedan University of Medical Science, ZAHEDAN, IRAN
}

\section{ABSTRACT}

Objective: Reactive hyperplastic lesions are one of the most common lesions of the oral cavity. Mast cells can be found in various oral lesions. However, the exact role of mast cells in oral reactive lesions is not fully understood. The aim of this study was to compare the mast cells count in various oral reactive lesions and to evaluate the correlation between the mast cells number and the intensity of inflammation.

Material and Method: This cross-sectional study was performed on 80 samples of oral reactive lesions including irritation fibroma, pyogenic granuloma, peripheral giant cell granuloma and peripheral ossifying fibroma (20 for each). Eight samples of normal oral mucosa were selected as the control group. To determine the mast cells count and the intensity of inflammation, Toluidine blue and Hematoxylin \& Eosin staining was performed respectively. The data was analyzed with SPSS (V.21), Kruskal-Wallis, Tukey and Spearman's correlation coefficient tests.

Results: In this study, a significant increase in mast cells count was found in oral reactive lesions compared to normal oral mucosa ( $<<0.001$ ). Difference of mast cell count between irritation fibroma and the peripheral giant cell granuloma groups ( $\mathrm{p}=0.023$ ), peripheral ossifying fibroma and peripheral giant cell granuloma groups $(\mathrm{p}=0.001)$ was statistically significant. There was a significant correlation between mast cell count and the intensity of inflammation in the irritation fibroma and pyogenic granuloma groups.

Conclusion: The finding of this study showed that mast cells count in peripheral ossifying fibroma and irritation fibroma were significantly higher than normal oral mucosa, so mast cells may have some role in the induction of fibrosis in oral reactive lesions.

Key Words: Mast cells, Oral cavity, Inflammation

\section{INTRODUCTION}

The oral mucosa is exposed to internal and external stimulation constantly and therefore develops a range of developmental, reactive, inflammatory and neoplastic diseases. Reactive hyperplastic lesions are common in the oral mucosa. These lesions are created in response to variety of stimuli and damage caused by chewing, food impactions, calculus, broken teeth and iatrogenic factors (1).

Kfir et al. classified reactive hyperplastic lesions as pyogenic granuloma (PG), peripheral giant cell granuloma (PGCG), peripheral ossifying fibroma (POF) and irritation fibroma (IF) (2). Despite chronic etiologic factors for all these lesions, they have different histopathological characteristics (3).

Mast cells (MCs) were discovered by Paul Ehrlich in 1878. These are immune cells that originate from the bone marrow and are scattered in all connective and mucosal tissues especially perivascular area. Also they are seen in the peripheral and central nervous systems. These include numerous granules in their cytoplasm (4-6).

(Turk Patoloji Derg 2016, 32:22-26)

Received : 24.07.2015 Accepted : 03.11.2015
MCs play a critical role in type 1 hypersensitivity reactions. They also synthesize and release many different chemical agents in response to various stimulations such as histamine, prostaglandin, tryptase, chymase, various cytokines (IL-3, IL-4, IL-5, IL-8, IL-13), as well as vascular endothelial growth factor (VEGF), basic fibroblast growth factors (BFGF) and transforming growth factor- $\beta$ (TGF- $\beta$ ) (7). Fibrosis is a collagen deposition process in which fibroblasts are the target cells. MCs can affect fibroblasts by releasing a wide range of biological active substances and have a synergistic or antagonistic effect on them (8). MCs play a role in the pathologic fibrosis processes in some conditions such as hypertrophic scars, chronic atopic dermatitis, liver cirrhosis, fibrosing alveolitis and cardiac fibrosis (9).

The exact role of mast cells in connective tissue is not yet fully understood. It is suggested that these cells have a role in cell regulation and in the control of the accumulation of connective tissue components (10).

Correspondence: Shirin SARAVANI

Department of Oral \& Maxillofacial Pathology, Oral and Dental Disease Research Center, School of Dentistry, Zahedan University of Medical Science, ZAHEDAN, IRAN

E-mail: shirin.saravani@gmail.com Phone: +98 5433414001 
MCs have a critical role in the development of inflammation in the oral mucosa in both early vasoinductive and acute to chronic inflammation transition which suggests that mast cells have a role in the employment of inflammatory cells and angiogenesis (10).

Since the role of mast cells in oral reactive lesions is still not fully understood and only few studies have been done in this subject $(4,6)$, the aim of this study to compare the mast cell count in oral reactive lesions and normal oral mucosa and also to determine the correlation between the number of these cells and the intensity of inflammation.

\section{MATERIAL and METHOD}

In this cross-sectional study, all cases diagnosed as IF, POF, PGCG and PG were obtained from the Department of Oral and Maxillofacial Pathology in the Dental School of Zahedan, Iran, over a period of 10 years. A total of 80 specimens were collected, including 20 cases for each category. Also 8 clinically normal gingival tissues from patients who had surgical removal for impacted third molar were selected as control. Clinicopathological data including age, gender and location were extracted from the patients' files. Specimens without clinicopathological data and sufficient paraffin-embedded tumor tissues were excluded. This study was approved by the ethics committee of Zahedan University of Medical Sciences (Project No. 6781).

The paraffin-embedded tissues were segmented into $5 \mu \mathrm{m}$ sections. Two sections were prepared for each case; one section was stained with $1 \%$ toluidine blue for detection of mast cells and second section was stained with hematoxylin and eosin for determination of the inflammation intensity. In toluidine blue staining, mast cell granules are seen purplish red and the nuclei sky blue in color.
All slides were observed by a pathologist that who was blinded to the clinicopathological data for each specimen using a light microscope (Nikon, Type2, Tokyo, Japan). Evaluation of mast cell count was performed in 10 microscopic fields in the hot spot (the most populated areas by mast cells) with a magnification of $x 400$. Then the total count of mast cells in $10 \mathrm{HPF}$ was considered as the mast cells count for each case. The inflammation intensity was also evaluated according to the following scale (3): 0 : absent; 1: mild (slight, scattered); 2: moderate (slightly diffuse or prominent scattered inflammatory cells); and 3: severe (prominent, diffuse).

Data analysis was performed using SPSS 21(SPSS Inc, Chicago, IL), Kruskal-Wallis, Tukey and Spearman's correlation coefficient tests. A p-value less than 0.05 was considered statistically significant.

\section{RESULTS}

This study was conducted on 88 samples, including 20 cases of IF, 20 cases of POF, 20 cases of PG, 20 cases of PGCG and 8 cases of normal oral mucosa. All demographic data related to these samples are summarized in Tables I and II.

In microscopic sections stained by $1 \%$ Toluidine blue, mast cells are mostly found in the lamina propria and perivascular area. They were predominantly located in peripheral regions of the lesions in PGCGs (Figure 1A-D).

Table III shows the average number of mast cells and intensity of inflammation in various reactive lesions. The average mast cell count in POF was higher than in all other lesions $(121.3 \pm 50.04)$ and normal oral mucosa had the minimum mast cell count $(27.8 \pm 20.4)$.

According to the Kruskal-Wallis test, the difference of mast cell count between study groups was significant $(\mathrm{p}<0.001)$.

Table I: Frequency distribution of study groups by gender and age

\begin{tabular}{|c|c|c|c|c|c|}
\hline \multirow{3}{*}{ Study groups } & \multicolumn{5}{|c|}{ Demographic data } \\
\hline & \multicolumn{2}{|c|}{ Gender } & \multicolumn{3}{|c|}{ Age } \\
\hline & $\begin{array}{l}\text { Male } \\
\mathrm{n}(\%)\end{array}$ & $\begin{array}{c}\text { Female } \\
\mathrm{n}(\%)\end{array}$ & Mean \pm SD & Min & $\operatorname{Max}$ \\
\hline POF & $4(20)$ & $16(80)$ & $34.05 \pm 11.58$ & 18 & 63 \\
\hline IF & $7(35)$ & $13(65)$ & $47.43 \pm 18.3$ & 13 & 80 \\
\hline PG & $7(35)$ & $13(65)$ & $27.38 \pm 14.2$ & 11 & 62 \\
\hline PGCG & $8(40)$ & $12(60)$ & $30.11 \pm 15.7$ & 8 & 52 \\
\hline NOM & $3(37.5)$ & $5(62.5)$ & $27.87 \pm 4.61$ & 21 & 35 \\
\hline
\end{tabular}

POF: Peripheral Ossifying Fibroma, IF: Irritation Fibroma, PG: Pyogenic Granuloma, PGCG: Peripheral Giant Cell Granuloma, NOM: Normal Oral Mucosa. 
Table II: Frequency distribution of study groups by location

\begin{tabular}{|c|c|c|c|c|c|c|c|}
\hline \multirow{3}{*}{ Study group } & \multicolumn{6}{|c|}{ Location } & \multirow{3}{*}{ Total } \\
\hline & \multicolumn{2}{|c|}{ Gingiva } & \multirow{2}{*}{ Buccal mucosa } & \multirow{2}{*}{ Tongue } & \multirow{2}{*}{ Lip } & \multirow{2}{*}{ Palate } & \\
\hline & Upper jaw & Lower jaw & & & & & \\
\hline POF & $13(65)$ & $6(30)$ & $0(0)$ & $0(0)$ & $0(0)$ & $1(5)$ & $20(100)$ \\
\hline IF & $4(21.1)$ & $4(21.1)$ & $4(21.1)$ & $2(10.5)$ & $2(10.5)$ & $3(15.7)$ & $19(100)$ \\
\hline $\mathrm{PG}$ & $12(66.6)$ & $2(11.1)$ & $3(16.7)$ & $0(0)$ & $0(0)$ & $1(5.6)$ & $18(100)$ \\
\hline PGCG & $9(45)$ & $7(35)$ & $3(15)$ & $1(5)$ & $0(0)$ & $0(0)$ & $20(100)$ \\
\hline NOM & $2(25)$ & $6(75)$ & - & - & - & - & $8(100)$ \\
\hline Total & $40(47.05)$ & $25(29.42)$ & $10(11.76)$ & $3(3.52)$ & $2(2.35)$ & $5(5.9)$ & $85(100)$ \\
\hline
\end{tabular}

POF: Peripheral Ossifying Fibroma, IF: Irritation Fibroma, PG: Pyogenic Granuloma, PGCG: Peripheral Giant Cell Granuloma, NOM: Normal Oral Mucosa. (In one case of IF and 2 cases of PG, location of the lesion was not recorded in the patient's file).
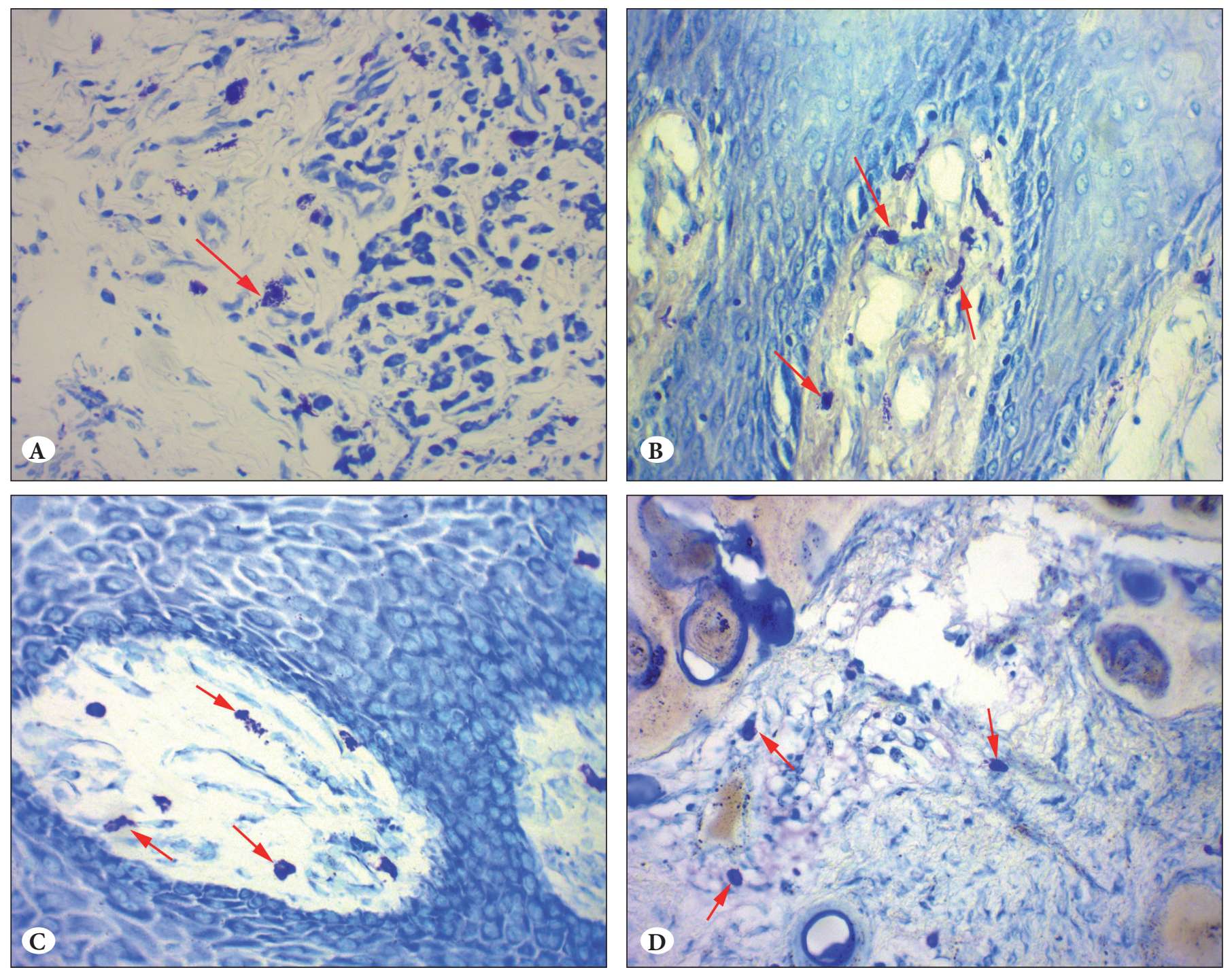

Figure 1: Mast cells (arrows) in oral reactive lesions: A) Mast cells with granules in peripheral region of a peripheral giant cell granuloma (Toluidine blue; $\mathrm{x} 400$ ). B) Mast cells in the superficial lamina propria and perivascular area in pyogenic granuloma (Toluidine blue; x400). C) Mast cells in irritation fibroma (Toluidine blue; x400). D) Mast cells in peripheral ossifying fibroma with a focus of ossification (Toluidine blue; $\mathrm{x} 400$ ). 
Table III: Mean and standard deviation of mast cells count and intensity of inflammation in study groups

\begin{tabular}{|l|c|c|}
\hline $\begin{array}{l}\text { Study } \\
\text { groups }\end{array}$ & $\begin{array}{c}\text { Mast cells count } \\
\text { in 10 HPF } \\
\text { Mean } \pm \text { SD }\end{array}$ & $\begin{array}{c}\text { Intensity of } \\
\text { inflammation } \\
\text { Mean } \pm \text { SD }\end{array}$ \\
\hline POF & $121.3 \pm 50.04$ & $2.05 \pm 0.68$ \\
\hline IF & $105 \pm 38.3$ & $1.75 \pm 0.71$ \\
\hline PG & $90.35 \pm 63.3$ & $2 \pm 0.85$ \\
\hline PGCG & $57.45 \pm 44.36$ & $1.75 \pm 0.55$ \\
\hline NOM & $27.8 \pm 20.4$ & - \\
\hline
\end{tabular}

POF: Peripheral Ossifying Fibroma, IF: Irritation Fibroma, PG: Pyogenic Granuloma, PGCG: Peripheral Giant Cell Granuloma, NOM: Normal Oral Mucosa.

In a comparison of the MC count between four study groups, the Tukey test showed that only the difference of mast cell count between IF and PGCG $(p=0.023)$ and also between POF and PGCG ( $\mathrm{p}=0.001)$ was statistically significant. In comparison of the number of the MCs between each group and normal oral mucosa, the difference of mast cell count between IF and normal oral mucosa ( $p$ $=0.018)$, and POF and normal oral mucosa $(\mathrm{p}=0.002)$ was statistically significant.

Using Spearman's correlation coefficient test, there was a significant correlation between mast cell count and the intensity of inflammation in IF $(r=0.445, \mathrm{p}=0.049)$ and in PG $(\mathrm{r}=0.732, \mathrm{p}<0.001)$.

\section{DISCUSSION}

Mast cells have local and systemic effects by releasing a variety of mediators in a degranulation process. Most of the mediators are stored in cytoplasmic granules while other mediators are released at the time of mast cell stimulation. Importance and role of cytokines derived from mast cells is not clear in some disorders. They may play a critical role in both physiologic and pathologic processes (10).

The histopathology of oral reactive lesions is usually dependent on the stage of the lesions which includes neovascularization and inflammation (11). Since mast cells include cytokines that cause these processes, their existence in these lesions may lead to better understanding of the pathogenesis (10). In the present study, the number of mast cells in the oral reactive lesions was compared. Few studies have been conducted for such a comparison.

According to our results, there was an increase in mast cell count in reactive lesions compared to the normal mucosa of the gingiva, which is similar to results from Farahani et al.(3), Reddy et al.(10) and Shojae et al. (6). In the present study, the mast cell count significantly increased only in POF and IF when compared to the normal mucosa of the gingiva that was similar to Reddy et al. (10). However, Shojae et al. (6) reported a statistically significant difference only between POF and normal oral mucosa. Farahani et al. showed statistically significant differences between all groups (IF, IFH, POF, PGCG) and normal oral mucosa (3). These differences are probably due to the type of technique and sample size of the studies. In fact, POF and IF have a more condensed fibrotic matrix compared to PGCG and PG (3), so the significant increase in mast cells count in these lesions is probably a sign of chronic inflammation that leads to fibrosis.

In vitro studies have shown the collagen synthesis and metalloproteinase induction in pulmonary fibroblasts caused by mast cells. In fact, mast cells can affect fibroblast functional behavior, followed by fibrotic processes. This process can be a result of the release of a series of fibrogenic cytokines such as platelet derived growth factor (PDGF), tumor necrosis factor (TNF- $\alpha$ ) and basic fibroblast growth factor (b-FGF). In addition, the main components in mast cell granules are the tryptase and chymase enzymes that have been proven to stimulate and induce the proliferation of fibroblasts and type 1 collagen synthesis $(3,12)$.

In previous studies, it has been shown that the mast cell count increases in lesions such as early stage of epulis (13), submucosal fibrosis (14), denture induced fibrous hyperplasia (DIFH) (7), inflammatory fibrous hyperplasia (15) and solitary fibrous tumor (16). In other studies, the cross-reaction of mast cells with fibroblasts and their role in collagen synthesis have been proven in diseases and pathologic conditions such as scleroderma, fibrosis of skin (17), and fibrotic transitions in minor salivary glands in patients with Sjogren's syndrome (18).

Murata et al.(13) showed that mast cells have a major role in neovascularization of granulation tissue. However, by increasing the fibrosis, the count of mast cells decreases. They also mentioned that the other cells such as macrophages and epithelial cells release fibrogenic cytokines exactly like the mast cells (13).

In our study, the mast cell count in PG was increased compared to normal mucosa but this was not statistically significant. In the Kamal et al.(4) study, the average count of intact and degranulated mast cells in PG was significantly higher than the normal mucosa. In addition, the average degranulated mast cell count was higher than in intact cases. This proves that the number of mast cells increases and degranulation occurs due to the stimulation 
by different etiologic factors. Then they cause vascular and inflammatory changes that lead to PG formation. This proves that mast cells may affect various stages of reactive lesion formation and connective tissue (4).

In this study, there was a positive correlation between mast cell count and the intensity of inflammation in IF and PG while in the Farahani et al. study (3), there was the same correlation in the IF and PGCG groups. This makes it obvious that mast cells have a role in inflammation. Chronic synthesis and release of TNF from mast cells may cause leukocyte migration and chronic inflammation, similar to what has been seen in lichen planus. Breakdown of connective tissue matrix or structural proteins of basement membrane that are produced by tryptase and chymase of mast cells may facilitate the tissue diffusion of leukocytes during the process of inflammation and other inflammatory lesions such as lichen planus (19). In our POF and PGCG samples, there was no correlation between mast cell count and intensity of inflammation which is similar to the Smith et al. study (20).

In conclusion, mast cells may have a role in the pathogenesis of the oral reactive lesions and induction of fibrosis. They may also be one of the factors that cause a variation in microscopic features in this kind of lesions with a common etiologic factor.

\section{REFERENCES}

1. Kadeh H, Saravani S, Tajik M. Reactive hyperplastic lesions of the oral cavity. Iran J Otorhinolaryngol. 2015;27:137-44.

2. Kfir Y, Buchner A, Hansen LS. Reactive lesions of the gingiva: A clinicopathological study of 741 cases. J Periodontol. 1980;51:65561.

3. Farahani SS, Navabazam A, Ashkevari FS. Comparison of mast cells count in oral reactive lesions. Pathol Res Pract. 2010;206:1515.

4. Kamal R, Dahiya P, Goyal N, Kumar M, Sharma N, Saini HR. Mast cells and oral pathologies: A review. J Nat Sci Biol Med. 2015;6:35-9.

5. Spoorthi BR, Vidya GS. Mast cell count analysis in oral inflammatory lesions, potentially malignant disorders and oral squamous cell carcinomas. International Journal of Scientific and Research Publications. 2013;3:1-4.

6. Shojaei S, Jamshidi S, Roshanaei G, Modabbernia S, Farzin B. Immunohistochemical expression of mast cell in oral reactive lesions. J Dent Shiraz Univ Med Sci. 2014;16:4-10.
7. Kiuchi M, Yamamura T, Okudera M, Souksavanh V, Ishigami $\mathrm{T}$, Iwase T, Warnakulasuriya S, Komiyama K. An assessment of mast cells and myofibroblasts in denture-induced fibrous hyperplasia. J Oral Pathol Med. 2014;43:53-60.

8. Levi-Schaffer F, Weg VB. Mast cells, eosinophils and fibrosis. Clin Exp Allergy. 1997;27:64-70.

9. Roberts IS, Brenchley PE. Mast cells: The forgotten cells of renal fibrosis. J Clin Pathol. 2000;53:858-62.

10. Reddy V, Bhagwath SS, Reddy M. Mast cell count in oral reactive lesions: A histochemical study. Dent Res J. 2014;11:187-92.

11. Günhan M, Bostanci H, Günhan O. Mast cell counting in fibrous gingival hyperplasias and giant cell granuloma. Ankara Univ Hekim Fak Derg. 1989;16:453-6.

12. Riekki R, Harvima IT, Jukkola A, Risteli J, Oikarinen A. The production of collagen and the activity of mast-cell chymase increase in human skin after irradiation therapy. Exp Dermatol. 2004;13:364-71.

13. Murata M, Hara K, Saku T. Dynamic distribution of basic fibroblast growth factor during epulis formation: An immunohistochemical study in an enhanced healing process of the gingiva. J Oral Pathol Med. 1997;26:224-32.

14. Huang S, Ling T, Wu H. Experimental study on aqueous areca nut extracts inducing oral submucous fibrosis in rats. II. Effection of mast cells on collagen metabolism. Hua Xi Kou Qiang Yi Xue Za Zhi. 1997;15:94-6.

15. Santos PP, Nonaka CF, Pinto LP, de Souza LB. Immunohistochemical expression of mast cell tryptase in giant cell fibroma and inflammatory fibrous hyperplasia of the oral mucosa. Arch Oral Biol. 2011;56:231-7.

16. Veltrini VC, Etges A, Magalhães MH, de Araújo NS, de Araújo VC. Solitary fibrous tumor of the oral mucosa-morphological and immunohistochemical profile in the differential diagnosis with hemangiopericytoma. Oral Oncol. 2003;39:420-6.

17. Wang HW, Tedla N, Hunt JE, Wakefield D, McNeil HP. Mast cell accumulation and cytokine expression in the tight skin mouse model of scleroderma. Exp Dermatol. 2005;14:295-302.

18. Skopouli F, Li L, Boumba D, Stefanaki S, Hanel K, Moutsopoulos HM, Krilis SA. Association of mast cells with fibrosis and fatty infiltration in the minor salivary glands of patients with Sjogren's syndrome. Clin Exp Rheumatol. 1997;16:63-5.

19. Walsh LJ. Mast cells and oral inflammation. Crit Rev Oral Biol Med. 2003;14:188-98.

20. Smith G, Smith AJ, Basu MK. Mast cells in human odontogenic cysts. J Oral Pathol Med. 1989;18:274-8. 